\title{
Publisher Correction: Gastric acid suppression promotes alcoholic liver disease by inducing overgrowth of intestinal Enterococcus
}

Cristina Llorente (1) 1,2, Peter Jepsen ${ }^{3,4}$, Tatsuo Inamine ${ }^{1,5}$, Lirui Wang ${ }^{1,2}$, Sena Bluemel ${ }^{1}$, Hui J. Wang (1) 1, Rohit Loomba', Jasmohan S. Bajaj ${ }^{6}$, Mitchell L. Schubert ${ }^{6}$, Masoumeh Sikaroodi ${ }^{7}$, Patrick M. Gillevet ${ }^{7}$, Jun Xu ${ }^{8}$, Tatiana Kisseleva ${ }^{8}$, Samuel B. Ho ${ }^{1,2}$, Jessica DePew ${ }^{9}$, Xin Du ${ }^{1}$ Henrik T. Sørensen ${ }^{4}$, Hendrik Vilstrup ${ }^{3}$, Karen E. Nelson ${ }^{9}$, David A. Brenner ${ }^{1}$, Derrick E. Fouts ${ }^{9}$ \& Bernd Schnabl ${ }^{1,2}$

Nature Communications 8:837 10.1038/s41467-017-00796-x; Article published online: 16 Oct 2017

In the original PDF version of this Article, which was published on 16 October 2017, the publication date was incorrectly given as 10 October 2017. This has now been corrected in the PDF; the HTML version of the paper was correct from the time of publication.

Published online: 12 December 2017

Open Access This article is licensed under a Creative Commons Attribution 4.0 International License, which permits use, sharing, adaptation, distribution and reproduction in any medium or format, as long as you give appropriate credit to the original author(s) and the source, provide a link to the Creative Commons license, and indicate if changes were made. The images or other third party material in this article are included in the article's Creative Commons license, unless indicated otherwise in a credit line to the material. If material is not included in the article's Creative Commons license and your intended use is not permitted by statutory regulation or exceeds the permitted use, you will need to obtain permission directly from the copyright holder. To view a copy of this license, visit http://creativecommons.org/licenses/by/4.0/.
\end{abstract}

(C) The Author(s) 2017

\footnotetext{
${ }^{1}$ Department of Medicine, University of California San Diego, La Jolla, CA 92093, USA. ${ }^{2}$ Department of Medicine, VA San Diego Healthcare System, San Diego, CA 92161, USA. ${ }^{3}$ Department of Hepatology and Gastroenterology, Aarhus University Hospital, Aarhus 8000, Denmark. ${ }^{4}$ Department of Clinical Epidemiology, Aarhus University Hospital, Aarhus 8000, Denmark. ${ }^{5}$ Department of Pharmacotherapeutics, Nagasaki University Graduate School of Biomedical Sciences, Nagasaki 852-8523, Japan. ${ }^{6}$ Division of Gastroenterology, Hepatology and Nutrition, Virginia Commonwealth University and McGuire VA Medical Center, Richmond, VA 23249, USA. ${ }^{7}$ Microbiome Analysis Center, George Mason University, Manassas, VA 20110, USA. ${ }^{8}$ Department of Surgery, University of California San Diego, La Jolla, CA 92093, USA. ${ }^{9}$ J. Craig Venter Institute, Rockville, MD 20850, USA. Correspondence and requests for materials should be addressed to B.S. (email: beschnabl@ucsd.edu)
} 